\title{
TRAGÉDIA GREGA E TEATRO CONTEMPORÂNEO? LENDO E TRADUZINDO ANTÍGONA PARA O PALCO CONTEMPORÂNEO COM O AUXÍLIO DE HÖLDERLIN
}

\section{GREEK TRAGEDY AND CONTEMPORARY THEATRE? READING AND TRANSLATING ANTIGONE FOR THE CONTEMPORARY STAGE WITH THE HELP OF HÖLDERLIN}

\author{
Kathrin Rosenfield \\ Universidade Federal do Rio Grande do Sul, Porto Alegre, RS, Brasil \\ Lawrence Flores Pereira \\ Universidade Federal de Santa Maria, Santa Maria, RS, Brasil
}

\begin{abstract}
Resumo: Este artigo apresenta uma experiência tradutória que visou, de antemão, o palco, sem desconsiderar, no entanto, a questão das diversas camadas da recepção crítica, da interpretação e da tradução. Para recuperar o potencial dramático obscurecido pelas convenções cristãs, a dramaturga e o tradutor valeram-se da versão desta tragédia do poeta alemão, Friedrich Hölderlin. Esta interpretação foi inserida no contexto brasileiro de expressão corporal, numa transposição da abordagem (crítica, teórica e tradutória) para uma produção cênica que envolveu música, dança, linguagem corporal e atuação.

Palavras-Chave: Tragédia, Antígona, Sófocles, Teatro, Tradução.
\end{abstract}

Abstract: This article presents a multi-layered experience of translation. Translation takes here several (literal and metaphorical) meanings. First, the transposition of a Greek text into modern Portuguese; second, the critical reception of valuable information from an inspired German poet, Friedrich Hölderlin, who previously translated the same text into German; third, the "translation" of the result of translator's and the critic's research into the artistic language of a stage production involving music, dance, body language, acting.

Keywords: Tragedy, Antigone, Sophocles, Theatre, Translation.

\section{Introdução}

A cultura luso-brasileira tem historicamente ignorado a tragédia como gênero. Todavia, as tradições orais e musicais brasileira fornecem componentes ideais para uma investigação crítica e criativa dos problemas e das potencialidades desta forma de arte antiga. A Poesia popular - executada, declamada e dançada - ainda está viva no interior brasileiro, no sertão. No serrado árido do Nordeste brasileiro, existe ainda a poesia cantada e dançada. Os festivais em torno das tradições de gado locais, como o Bumba - meu boi, combinam as procissões corais talvez semelhantes aos rituais da Grécia Antiga com danças carnavalescas que sobreviveram também nos ritos medievais das danças e corridas com cavalos de madeira.

Os duelos verbais das trovas e pelejas ainda são praticados como um vívido combate opondo dois poetas - exatamente como os poetas gregos ou 
como os menestréis medievais; Hoje, o carnaval reina não só no Nordeste, mas em todo o Brasil: em Olinda e inúmeras outras cidades podem fazer parte do grande "corpo" de pessoas dançando e cantando juntas, fazendo a experiência viva do corpo de Baile, e do estado de consciência peculiar para o qual no transportam o lirismo e a dança do Coro grego.

Apesar do aparente desinteresse pela tragédia, o Brasil provou ser um lugar ideal para refletir sobre os problemas desta forma de arte antiga. As diferenças culturais permitiram um novo foco sobre os componentes mais vivos da poesia trágica (apontados, na Europa, por artistas como Hölderlin e Nietzsche). $\mathrm{Na}$ verdade, o desinteresse brasileiro em tragédia abriu uma lacuna produtiva para uma reflexão sensível sobre o que as pelejas de canto e dança como os concursos de canto de Alcman ou Teócrito, concursos que Nietzsche tinha em mente quando escreveu sobre a tragédia grega.

Estes eram, e são, os impulsos poderosos para compreender melhor idéías como o "Espírito da Música", o "ritmo" e a "vivacidade", que vieram a ser as palavras-chave das abordagens modernas ou anti-classicistas dos clássicos. Mencionemos last but not least, o forte impulso dos Concretistas, em particular de Haroldo e Augusto de Campos, que nos anos 1970 e 80, foram tão criativos na reconciliação do conhecimento acadêmico, da filologia e da filosofia com a invenção artística. Suas versões re-criaram (mais do que traduziram) a graça de sons e sentido, conflagrando em imagens instantâneas a densidade de longas reflexões.

Este substrato brasileiro formou o lastro do projeto inusitado de encenar a Antígona de Sófocles de um outro modo, recriando-a de acordo com o "Geist der Musik" (Espírito da Música): de acordo com os critérios poéticos do "ritmo" que Nietzsche e Hölderlin consideravam indispensáveis para recriar o teatro grego no âmbito da cultura contemporânea. Um exaustiva pesquisa acadêmica sobre a Antígona de Sófocles, lida e reinterpretada através da estranha perspectiva de Friedrich Hölderlin, forneceu preciosos impulsos para a nova tradução, e para o trabalho no palco. Testamos as idéias de um coro dançante e cantante em oficinas com bailarinos e atores; organizamos leituras dramáticas para testar a tradução em versos de Lawrence Flores Pereira. Estes esboços de re-criação da peça tomaram sua forma definitiva graças ao encontro com o diretor de teatro Luciano Alabarse, que estava disposto a encenar a tragédia com a tradução de Lawrence e a dramaturgia de $\mathrm{K}$. Rosenfield. Mais que isto, associou o compositor Arthur de Farias, que transpôs os versos ritmados de Lawrence na trilha sonora da peça, dando destaque aos seis hinos cantados pelo Coro.

A coreógrafa Carlota Albuquerque responsabilizou-se pela linguagem corporal que sugeriu de modo subliminar a complexidade semântica do texto. Ao todo, o elenco compreendia 36 pessoas - dançarinos, músicos, cantores, atores, a figurinista... , cenógrafa... E a iluminador a Claudia de Bem - reunidos 
num experimento multi- dimensional com o texto - o original de Sófocles intermediado por diferentes tradutores e interpretes.

A idéia central era a superação da convencional polarização desta peça. Pois Antígona costuma ser vista como uma mártir cristã sacrificada pela tirania brutal de Creonte, o que transforma a tragédia grega em um exemplum cristão. Como sair da lógica do bem e do mal? Como recuperar o paradoxo grego (e moderno) e a ironia trágica de Sófocles? Como dar nova vida a um drama soterrado pelos conceitos de Hegel e Heidegger, Freud e Lacan, de Knox, Jebb, Dawe e Nussbaum, entre muitos outros?

\section{Hölderlin e o caminho inovador da sua "fria neutralidade"}

Antígona e Creonte não são figuras do bem e do mal: são dois opositores, ambos com razões de peso, enredados no conflito trágico. Quando Antígona lamenta, no prólogo, os sofrimentos ininterruptos de sua estirpe, ela evoca não só o miasma que pesa sobre a linhagem dos Labdácidas, mas também a coragem de enfrentá-lo, sempre de novo. O incesto e o fratricídio são poluições religiosas que provocam uma vergonha (desonra objetiva) quase insuportável. O desânimo de Ismena é a reação normal a esse tipo de abalo, ao passo que Antígona surpreende com sua firmeza em enfrentar a mácula que ameaça sua casa. O contraste entre as irmãs foi claramente sublinhado na nossa encenação pelos sinais cromáticos da vestimenta (o amarelo fraco de Ismena contrastando com o púrpura forte de Antígona), pelas posturas e os gestos, pelos fisiotípos diametralmente opostos (Figuras 2 e 8).

Antígona ousa questionar a autoridade de Creonte, insurgindo-se contra o general coberto de méritos na sua função de conselheiro-regente. $\mathrm{Na}$ noite anterior, ele salvou Tebas da destruição, sacrificando seu filho Megareu, coroando gloriosamente seus longos serviços meritórios. Eis o pano de fundo do conflito envolvendo o direito de enterrar Polinice. Por isto, o Coro é imobilizado numa postura de "neutralidade gélida" como diz Hölderlin, nunca posicionando-se a favor de Antígona, contra Creonte. Apesar da fidelidade à casa real dos Labdácidas, os anciãos consideram que Creonte - que pertence a uma linhagem que não tem direito ao trono, apenas às funções de conselheiro e regente - tem razões a serem ponderadas e que o permitem ocupar o trono.

Isto não significa que eles não gostariam de ver ambos os irmãos enterrados. O enterro é um costume que a humanidade pratica desde tempos imemoriais e que, por isto, é considerado sagrado. Mesmo assim, inúmeros mitos e fatos históricos mostram que a mutilação do corpo do inimigo é uma prática comum na Grécia arcaica e clássica (seu alvo é enfraquecer o espírito do morto e, com isto, sua estirpe; cf. Ésquilo, Coéforas, 440 e nota do v. 429 ss.). Contra estas práticas inspiradas pelo receio e o ódio, Antígona reivindica o sepultamento do irmão morto como uma prática inalienável. O decreto the 
parece ser uma medida arbitrária que fere as leis divinas (kerygma designa, aliás, uma proclamação numa situação de emergência). Mas essa reivindicação não elimina as inquietudes e as superstições envolvendo os cadáveres de Eteocle e de Polinice. Afinal, os fratricidas causaram uma nova poluição e o sangue vertido no solo representa um real perigo para a cidade. O texto grego designa os fratricidas ora como suicidas do mesmo [sangue], sugerindo, de um lado, que eles cometeram um novo miasma, de outro, que este derramamento do sangue pudesse ser um sacrifício báquico, um ritual que liberaria a cidade da discórdia. Os anciãos propõem esta solução (logo veremos mais em detalhe como Hölderlin detectou esta visão inspirada no primeiro canto coral). Creonte, no entanto, acredita que a desmedida dos filhos incestuosos poluiu novamente a cidade e que a mutilação do cadáver de Polinice é um rito necessário de despoluição.

São duas visões diferentes que colocam a questão difícil de resolver: Afinal, Polinice defendeu seu direito ao trono, Eteocle a segurança de sua cidade. Para escapar a este tipo de contradição, Creonte ignora os costumes e justifica seu decreto com um argumento estritamente moral e cívico: um agiu como amigo, o outro como inimigo da cidade.

Eis a trama mais evidente e superficial da tragédia. Mas este conflito é potencializado por outros, menos evidentes (pelo menos para o espectador moderno, que não conhece mais as práticas do mundo antigo). Eles tocam as representações míticas, genealógicas e políticas da cidade de Tebas. A arte do poeta entrelaça esses raciocínios diversos num nó impossível de desatar.

O motivo genealógico aflora já no Prólogo, onde Antígona mostra indignação por o decreto ter sido proclamado não somente para a cidade e Ismena, mas também para ela. Falando com certa condescendência do «bom (ou grande) Creonte», ela marca um desnível de estatuto entre sua própria linhagem e a de Creonte. Essa desigualdade dos estatutos está fixada na mitologia anterior aos trágicos. Laio, Édipo e Antígona descendem de Lábdaco, Polidoro e Cadmo, fundador de Tebas, isto é, eles pertencem a uma linhagem de reis. Creonte e seus ancestrais Meneceu e Oclaso, ao contrário, pertencem a uma estirpe de conselheiros reais e de regentes. Este fato coloca a questão de quem tem o direito de assumir o trono como verdadeiro rei. A arte de Sófocles conecta discretamente essa pergunta que aflora no mito tebano com idéias modernas que pertencem ao imaginário jurídico-político do século quinto. Nesta época, existia em Atenas uma instituição (o epiklerado) que garantia à filha de um rei morto sem descendência o direito e o dever de parir um descendente para o seu pai. Se Creonte fosse um contemporâneo de Sófocles, seria obrigado a casar Antígona, no regime do epiclerado, com seu mais próximo parente. Neste tipo de casamento, o noivo deve renunciar a uma descendência própria, cumprindo o dever de engendrar um filho para seu sogro. Eis por que, no rito nupcial, a noiva epikler permanece no lar de seus 
ancestrais. Imaginariamente, ela é esse lar, isto é, a matriz ou raiz da descendência por vir - o que se reflete no nome Antígona (anti = no lugar da, gone = descendência). O Coro chama Antígona e Ismena de « últimas raízes » da casa dos labdácidas, e deposita nelas uma esperança que se revela nos gritos de desespero que os anciãos lançam quando percebem que a morte de Antígona é iminente.

É evidente que Creonte, preocupado com a poluição religiosa (miasma) da cidade pelo incesto e derramamento do sangue de parentes vê qualquer tipo de casamento entre Hemon e Antígona apenas como mais uma aliança nefasta. Afinal, Ismena e Antígona são as "últimas raízes » de uma estirpe que carrega a tara de uma maldição terrível. Seu dever político (seja como regente, seja como rei) é a purificação da cidade e o restabelecimento da ordem. Apesar da fuga do exército agressor, esta não é uma tarefa fácil. Como as catástrofes ininterruptas mostraram que os Labdácidas sempre de novo suscitam a ira divina, Creonte procura distanciar-se da antiga linhagem. Tudo indica que Creonte - que serviu Édipo como fiel conselheiro e assegurou a tomada de poder de Polinice e Eteocle - sinta-se agora obrigado a assumir o poder não mais como regente, mas como rei - ou como tyrannos, isto é, como governante que conquista o poder pelo seu próprio mérito: o mérito de romper com a antiga maldição instaurando uma nova linhagem não poluída.

Por isto, Creonte e Antígona vestem, ambos, a cor púrpura privilégio de reis e imperadores. Afinal, eles se disputam o direito ao trono, o direito a sacrificar no altar que está no centro do Palácio, o fogo-lar de Zeus Herkeios (Fig. 1 e 3).

Cabe aqui lembrar o imaginário que os contemporâneos de Sófocles compartilhavam e que nós perdemos. Todos eles conheciam uma instituição legal ateniense chamada de epiclerado. Em razão das famílias gregas serem normalmente patrilineares, uma casa sem herdeiros do sexo masculino seria ameaçada de extinção. O instrumento jurídico do epiclerado permitiu, portanto, a uma filha órfã sem irmãos vivos transmitir o nome e a propriedade de seu pai. Seu primo mais próximo era obrigado a se casar com ela e seus filhos eram considerados, não como os filhos de seu pai, mas, como filhos e herdeiros do pai da noiva. Devido à morte de seus dois irmãos, Antígona tornou-se uma epicler, e Creonte é obrigado a casar seu último e único filho Hemon com ela o que significa que ele, Creonte, não teria descendência. A situação é grave não só para Antígona, também para Creonte.

Com esse conhecimento, somos capazes de apreciar as geniais alterações poéticas de Hölderlin. Com um único pronome possessivo, ele permitiu a Antígona afirmar seu privilégio de ser e representar o (fogo)-lar do palácio real. Ela diz: "Porque o MEU Zeus não ditou aquela lei". Com a autoconfiança de uma filha epicler que conta com a proteção de Zeus Herkeios, o Zeus "dos muros", que era tão identificado com a casa que um ateniense 
pediria a outro o seu endereço perguntando "Onde está o seu Zeus Herkeios?". ${ }^{14} \mathrm{O}$ "meu Zeus" de Antígona recebe um eco imediato na resposta de Creonte, que habilmente tenta reduzir a arrogante princesa epicler ao status de uma rebelde sob sua proteção patriarcal e sujeita aos deuses do seu lar:

Doch wenn sie schon

Von meiner Schwester und Verwandtesten,

Vom ganzen Gotte meines Herdes da ist,

Dem allem ungeachtet meidet sie

Den schlimmen Tod nicht.
Filha de minha irmã, mais unida ao meu sangue

Que todos os que em minha casa adoram Zeus, Nem ela, nem a irmã quiseram se safar

Da morte mais atroz

A tradução inglesa de 2001 da Antígona de Hölderlin, feita por David Constantine, é bastante diferente da nossa: procuramos por alterações insistentes de Hölderlin (Meu Zeus - Meu lar): "What if she is the / Stuff of my sister and my closest kin / And of the whole god of my hearth. No matter of all that, she shall not evade / A bad death."

Em vez do início afirmativo "Mesmo se [ela for minha parente]", encontramos um questionamento "E se...". No entanto, o tempo futuro de "Ela não deve escapar / de uma morte ruim", sugere que Creonte está se referindo à sua própria determinação de condená-la e matá-la. Hölderlin claramente rende a Creonte uma retórica cuidadosa, que tenta apontar ao seu ato rebelde, que introduz blasfêmia no sagrado centro do palácio - de sua posse, no seu próprio lar.

$\mathrm{Na}$ nossa encenação, a rivalidade é visual e sensivel, não só na vestimenta (púrpura), mas também nos matizes selvagens da atriz sombria e forte, ao mesmo tempo em que a altiva e nobre; a violência contida de seus gestos, a energia de suas posturas, suas atitudes apaixonadas e ferozes transmitiam a sorte e a grandeza dos labdácidas - e sua origem selvagem: afinal, as casas nobres descendem dos spartói, dos monstros "semeados" (Fig. $1,2$ e 3$)$.

É neste polígono de forças - genealógicas e jurídicas, políticas e religiosas - que se joga a tragédia de Sófocles. Nos diálogos, sempre inconclusivos, os protagonistas esgotam sua capacidade de argumentar. No horizonte desses saberes e discursos historicamente determinados, abre-se um além difícil de nomear, uma Necessidade que escapa ao saber seguro do homem.

O destino na tragédia - e em particular na tragédia de Sófocles - é o imponderável e os acasos entendidos como forças ativas que têm o poder de alterar o sentido das nossas intenções e os efeitos de nossos atos voluntários.

${ }^{14}$ Cf. Jon D. Mikalson, Ancient Greek Religion, Oxford, Blackwell, 2010, "Religion in the Greek Family, 125. 
É herói o homem que sabe ir ao encontro desse imponderável, tornando necessário (não mero acaso) o que é a sorte, o destino.

O imponderável em Antígona surge sob a forma de discretos sinais da selvageria que marca os primórdios de Tebas. O herói fundador, Cadmo, matou o dragão (guarda da fonte) que devorou seus companheiros de armas. Guiado pelo oráculo, ele semeia seus dentes na terra e desta nasceram os « semeados » (spartoi), isto é, seres que desconhecem a geração humana (união de um pai e de uma mãe). A monstruosidade da geração unilateral (autogeração) pela terra-mãe manifesta-se na violência desmedida destes filhos. Recém nascidos, estes rebentos da Terra tebana precipitam-se uns contra os outros, aniquilando-se mutuamente. O símbolo dessa selvageria é a lança tatuada no corpo dos espartos: «Dizem que a lança tatuada sobre os spartoi, no momento em que saíram da gleba de terra que lhes deu à luz e que os nutriu, permaneceu durante muito tempo o signo característico desta raça », comenta um autor tardio. A raça dos espartos, como os Gigantes na Teogonia de Hesíodo, não é propriamente humana. O estigma da lança é o signo de uma desmedida que desconhece a sociabilidade humana. Esta somente poderá ter início quando Cadmo une seus filhos (humanos) aos cinco sobreviventes dessa estirpe monstruosa. As grandes linhagens tebanas descendem, portanto, de uma raça selvagem. Sua natureza excessiva e desordeira (a bybris violenta) manifesta-se, ao longo das gerações, nas infelizes irregularidades da ordem familiar e da transmissão do poder. Os laços da família são distorcidos (senão anulados) pelo incesto, pela exposição do filho, pelo parricídio e o fratricídio. Essas desordens repercutem na transmissão do poder que não passa de pai para filho, mas é obliquamente desviado para tios maternos, antes de voltar para a linha principal. A ameaça dessas formas selvagens (isto é, sub- e sobrehumanas) de convivência aflora sobre tudo nas densas imagens dos hinos que sobre determinam todo o texto (Fig. 4 e 7).

As nuanças do fundo musical e lírico dos cantos corais fazem parte da ironia trágica. Nesses matizes esboça-se uma experiência do ser humano que se situa além dos argumentos. No poema trágico cotejam-se duas formas de expressão - distintas tanto do ponto de vista estilístico, como do conteúdo. Se os diálogos tendem para a clareza da argumentação, os cantos corais suspendem as nítidas posições do debate numa expressão cantada (e dançada). Nesta, o pensamento se encontra em constelações complexas, e a densidade da expressão visa algo nebuloso que foge à compreensão racional e que parece ser reservado à inteligência dos deuses ou dos adivinhos. Nos diálogos, ao contrário, afirma-se o esforço de ordenar e controlar os acontecimentos graças à reflexão e a um saber compartilhado por todos. 


\section{A importância da lírica coral para a interpretação}

Hölderlin foi provavelmente o leitor que melhor penetrou no pensamento implícito que subjaz à lírica de Sófocles. Por isso, a presente tradução segue em alguns momentos as sugestões hölderlinianas sobretudo na versão dos seis hinos. Estes não interrompem a ação, mas medeiam as transições de um episódio ao outro. O Coro sofocliano é ainda um verdadeiro personagem do drama. $O$ que representam estes anciãos tebanos que acompanham quase toda a ação? Seriam eles o símbolo do consenso cívico ou democrático, da justa medida ou da prudência sensata dos homens velhos e experientes? Todas essas sugestões captam aspectos de uma categoria social muito respeitada na Grécia antiga. Mas a tragédia torna muito mais complexa esta figura do imaginário cotidiano.

O que sobressai nos seus esforços de permanecerem judiciosos, equitativos e neutros, é uma infeliz - e muito humana - oscilação entre a lucidez e a cegueira, entre a sabedoria e o desamparo, entre a frieza e o entusiasmo. Hölderlin elaborou com particular sutileza a armadilha dos esforços conciliadores da imparcialidade, mostrando ora como os anciãos se abandonam a elas impregnados pela simpatia e pela admiração que reservam aos Labdácidas (por Eteocle e Polinice no Párodo, por Antígona em diversas passagens), ora como eles se disciplinam para auxiliar o novo governo, exigindo de si mesmos e dos protagonistas o cumprimento das regras e dos preceitos racionais que ordenam a vida da sociedade.

Quem lê os hinos de Antígona em traduções convencionais, certamente imagina o Coro dos anciãos tebanos como um conjunto solene e lento, grave e comedido. No entanto, em várias passagens estes graves dignitários da cidade revelam sua afinidade apaixonada pela heroína. Esta fica apenas parcialmente contida e irrompe, sempre de novo, em certos gestos espontâneos. A versão hölderliniana do primeiro hino deixa aflorar essas afinidades que ligam o Coro ao temperamento trágico dos Labdácidas.

Essa empatia com a heroína intempestiva (e com os irmãos que acabaram de morrer) poderia vir a expressar-se também em gestos ambíguos que sobre determinam a solene entrada em cena dos anciãos. A gravidade do cortejo poderia, momentaneamente, dissolver-se em gestos bruscos, saltos e quedas, nas quais se anuncia a dificuldade de manter o equilíbrio numa cidade que perdeu a medida normal dos procedimentos regulares. Daí a importância de um coro grande, que se expressa de forma não conceitual, através de ritmo, música, dança e energia. Eis algumas imagens do coro de 16 integrantes, cantando acompanhados por orquestra e percussão (Fig. 4, 5, 6 e 7).

Os anciãos de Sófocles encarnam (exatamente como Cadmo e Tirésias nas Bacantes de Eurípides) a infeliz e insolúvel polaridade do mito tebano: de um lado, eles compreendem a inspiração dionisíaca: o primeiro e o 
último dos cantos corais exaltam precisamente o transe báquico, o pendor pela radical dissolução. De outro lado, eles procuram controlar esses elãs inquietantes e perigosos reconhecendo os legítimos esforços de Creonte pelo restabelecimento da ordem. A empatia com a inspiração báquica irrompe no párodos (hino de entrada), onde os anciãos evocam Eteócles e Polinices menos como adversários numa guerra ou causa política, do que como guerreiros em transe, possuídos por Baco. O que sobressai nesses versos não é tanto a oposição dos irmãos como adversários, mas os elos íntimos e fusionais que o delírio báquico (thiase) estabelece entre eles (Fig. 7).

Com efeito, no imaginário da antigüidade, a possessão dionisíaca tende a anular todas as fronteiras da sociabilidade política (diferenças hierárquicas entre categorias sociais), aproximando todos os membros da polis (cidadãos e escravos, homens e mulheres) dos outros seres vivos do cosmos (animais, plantas, etc.). O entusiasmo do Coro no primeiro canto assinala muito discretamente o problema central que decorre da maldição de Tebas: a dificuldade de manter a justa medida entre a ordem hierarquizada e a fusional, honrando judiciosamente as leis de Zeus (protetor do Estado regrado) e as de Dionysos (deus dos mistérios telúricos).

Em resumo: a tradução de Hölderlin, por mais difícil que seja, é poeticamente mais rica do que a maioria das reconstruções filológicas e filosóficas deste drama de Sófocles. Olhando de forma mais atenta, a "radicalização" de Hölderlin dos elementos elípticos e descontínuos do texto grego não são apenas uma primeira exploração da dimensão estranha da linguagem como o "lugar" dos processos por meios dos quais um sujeito exilado e perdido tece sua (moderna) consciência (Steiner, p. 75).

A lógica-poética de Hölderlin também parece produzir perspectivas surpreendentes sobre facetas até agora negligenciadas no que concerne à sensibilidade, à mente e à imaginação dos contemporâneos de Sófocles. Nossa leitura tanto do texto de Sófocles quanto do de Hölderlin objetiva apontar quantas portas continuam abertas nos mesmos trechos que George Steiner apontou - como exemplos da ideia de Benjamin - de que a veemência da tradução radical de Hölderlin fecharia "as portas por trás do tradutor" (Steiner p. 74, referindo-se a Benjamin, 1923).

Ao ultrapassar o pórtico das versões de Hölderlin, vemos não só o sujeito moderno desequilibrado e descentralizado, mas a intrigante modernidade da consciência mítica grega. Capturar a veemência dramática desses vislumbres foi o desafio da nossa encenação da peça em Porto Alegre: agitar as raízes esquecidas de um obscuro fundo mítico (a origem meio divina, meio humana da cidade de Tebas) (Fig. 14-16). As tensões entre a natureza e a cultura continuam a ser as nossas, embora normalmente não pensemos nelas com as metáforas do passado arcaico tebano. Por outro lado, tendemos sim a nos identificar, vez ou outra, com as inovações da pólis democrática clássica - e 
esta é a razão do porquê precisarmos tanto dos insights de Hölderlin. Eles mostram como sustentar o otimismo das esperanças iluministas no interior do sereno e alegre pessimismo grego.

Recebido em 30 de Julho de 2013. Aceito em 15 de Novembro de 2013.

\section{REFERÊNCIAS}

HEGEL, G. W. F. Phenomenology of Spirit (1807). Trans. and ed. A.V. Miller. Oxford: Oxford University Press, 1977.

HÖLDERLIN, Friedrich, 'Antigonä' and 'Anmerkungen zur Antigonä' (1804), Hölderlin Werke und Briefe Band 2. Frankfurt am Main: Insel Verlag 1969; 737-783 and 783-790. NIETZSCHE, Friedrich. Die Geburt der Tragödie (1872). Frankfurt am Main: Insel Taschenbuch, 1987.

MEZZADRI, Bernard. Étéocle pris au piège du cercle. Les Tragiques grecs, Revue Europe, January-February, 1999, p. 235-247.

MIKALSON, Jon D. Ancient Greek Religion, Oxford, Blackwell, 2010, "Religion in the Greek Family, 125.

Rosenfield, K.H. Antigone. Sophocles' Art, Hölderlin's Insight. Aurora: The Davies Group Publishers, 2010. p99-121.

SEGAL, Charles. Tragedy and Civilization: An Interpretation of Sophocles. Norman, OK: University of Oklahoma Press, 1999.

STEINER, George. Antigones: How the Antigone Legend Has Endured in Western Literature, Art, and Thought. New Haven: Yale University Press, 1996. 